\title{
Efectos de la reforma protestante en el sistema de relaciones internacionales de Europa Occidental
}

\author{
Diego Canales Ramírez ${ }^{1}$ \\ Recibido: 8 de enero de 2015 - Aceptado: 20 de marzo de 2015
}

\begin{abstract}
Resumen
Las críticas de Martín Lutero a la Iglesia Católica provocaron una fuerte convulsión en el seno de la sociedad occidental, pero también provocaron un cambio ideológico que repercutiría fuertemente en el sistema de relaciones internacionales de Europa Occidental, al generar una polarización entre dos bloques de Estados claramente enfrentados. Por un lado, se encontraban los países que adoptaron la Reforma, especialmente aquellos del norte de Europa, sobre todo Inglaterra, Suecia y Dinamarca, y por el otro lado, aquellos que aún seguían fieles ideológicamente al mandato del papado, como España. La Reforma permite a los Estados que adoptan dicha confesión el control de la Iglesia por el Estado, y a través de ésta, obtener beneficios económicos que permiten el enriquecimiento de las arcas fiscales, pero que generaron una separación en Europa entre un bloque católico y otro protestante, que conducirían a enfrentamientos armados entre ambos.
\end{abstract}

Palabras clave: Reforma Protestante, Iglesia, Relaciones Internacionales, Europa

\section{Effects of the protestant reformation in the international relations system in Western Europe}

\begin{abstract}
Martin Luther's criticism about the Catholic Church provoked a strong convulsion within Western society, but also an ideological change that would impact heavily on the system of international relations in Western Europe, generating a polarization between two blocks of States clearly confronted. On the one hand, there were countries that adopted the Reformation, especially those in Northern Europe, as England, Sweden and Denmark, and on
\end{abstract}

Chileno. Doctorando en Historia, Programa Europa y el Mundo Atlántico: Poder, Cultura, Sociedad, dictado por el Instituto de Historia Simancas, Universidad de Valladolid, España. Becario Erasmus Mundus PEACE. Profesor Facultad de Arquitectura, Urbanismo y Paisaje, Universidad Central de Chile. E-mail: diegomatias.canales@alumnos.uva.es 
the other hand, those who were still ideologically faithful to the mandate of the Papacy, as Spain. The reform allows States adopting such a confession to have control over the Church and through it, to get economic benefits that allow the enrichment of the treasury, but that created a separation in Europe between Catholics and Protestants leading to armed conflicts between them.

Keywords: Protestant Reformation, Church, international relations, Europe

\title{
Efeitos da reforma protestante no sistema de relações internacionais da Europa Ocidental
}

\begin{abstract}
Resumo
As críticas de Martín Lutero a Igreja Católica provocaram uma forte convulsão no seio da sociedade ocidental, mas também provocaram uma mudança ideológica que repercutiu fortemente no sistema de relações internacionais da Europa Ocidental, ao gerar uma polarização entre dois blocos de Estados claramente enfrentados. Por um lado, encontram-se os países que adotaram a Reforma, especialmente aqueles do norte da Europa, especialmente Inglaterra, Suécia e Dinamarca, e por outro lado, aqueles que ainda eram fiéis ao mandato do papado, como Espanha. A reforma permite aos Estados que adotam dita confissão o controle da Igreja sobre o Estado e, através dela, obter benefícios económicos que permitiram o enriquecimento das arcas fiscais, mas que geraram uma separação na Europa entre um bloco católico e outro protestante, que conduziriam a confrontos armados entre os dois.
\end{abstract}

Palavras-Chave: Reforma Protestante, Igreja, Relações Internacionais, Europa.

Los trescientos años que abarcan desde los siglos XIII al XVI representaron un periodo de esplendor sin precedentes en la sociedad occidental. A los avances en tecnología logrados gracias al contacto entre los árabes que invadieron la península Ibérica y la sociedad occidental, se sumaron nuevas filosofías que condujeron a la crítica de uno de los pilares de la sociedad medieval: la preeminencia de la Iglesia en los asuntos temporales. Dicha institución se hallaba sumida en una grave crisis no solo ideológica, sino también moral, y no podía responder a las demandas de la sociedad de la Baja Edad Media, una sociedad eminentemente sacralizada, donde no existían barreras entre lo natural y lo sobrenatural, entre el cielo y la tierra, convertida esta última en un inmenso campo de batalla, cuyos territorios y población eran disputados por Dios y su eterno rival, Satanás. Por ello, las personas tenían la acuciante preocupación de asegurar la salvación mediante un sistema abigarrado de protecciones contra la amenazante condenación eterna.

Esta amenaza no era fruto de una fértil imaginación, sino que tenía una correspondencia con una realidad claramente peligrosa. Durante toda la Edad 
Media, el cristianismo vivió rodeado de hostilidad, que conllevó a la definición de la unidad como tarea principal no solo de la Iglesia, sino también de los monarcas y señores feudales. Solo se toleraba el judaísmo, aunque separado por completo del mundo cristiano y llevando un signo que lo identificase. No obstante, la crisis de la Iglesia generó una fuerte crítica de teólogos heterodoxos como John Wyclif y su colega checo Jan Hus, pero la más fuerte fue la del teólogo y monje agustino Martín Lutero, quien con sus 95 tesis no solo provocaría un gran debate en el seno académico, sino también un barranco ideológico que dividió a Europa en dos bloques claramente antagónicos, una polarización que solo concluyó tras la sangrienta guerra de los Treinta Años y el reconocimiento de la preeminencia de los príncipes y señores para elegir la confesión de sus súbditos.

Desde esta idea clave, el presente trabajo se organiza en torno a tres ejes claramente diferenciables. En primer lugar, se expondrán los fundamentos de las críticas de Martín Lutero, desde el punto de vista político, para luego ver las reacciones y la expansión de sus ideas, que generaron la formación de un bloque protestante opuesto al bloque católico, y se finalizará con el primero de los grandes enfrentamientos entre ambos bloques: la guerra entre Carlos V y la Liga de Esmacalda, que concluyó en la batalla de Mühlberg (1547).

\section{La crisis de la Iglesia en la Baja Edad Media}

Uno de los rasgos más característicos de la Edad Media fue el poder casi absoluto que ejercía la Iglesia, no solo en los aspectos espirituales, sino también temporales. Apoyada por los monarcas y los señores feudales, la Iglesia persiguió con crudeza toda forma de pensamiento o doctrina que se opusiera a sus designios o interpretaciones, como ocurrió en el caso de los cátaros del Languedoc, quienes fueron completamente derrotados por las tropas papales en la cruzada del siglo XIII. Sin embargo, en este panorama no faltaban señales tempranas de crisis. Algunos sacerdotes y monjes se lamentaban profundamente por el abandono de los votos por parte de sus compañeros, criticando abiertamente al papado por su ambición de poder y gloria. En los ambientes universitarios, la apasionada búsqueda de soluciones racionales condujo a algunos doctores a recordar enérgicamente que la trascendencia divina resultaba inaccesible para el entendimiento humano (Rapp, 1979: VII). Dichas críticas irían generando, con el tiempo, una conflictividad en el seno de la Iglesia, y con ello, un cisma cuyas consecuencias serían más duraderas que las provocadas por la llamada Cautividad Babilónica que dividió al papado en el siglo XIII.

La Iglesia estaba en crisis y ello era una realidad evidente para cualquier entendido. Muchos clérigos jamás habían visitado sus parroquias, y contrataban suplentes que eran reclutados de cualquier modo y eran mezquinamente 
pagados. Una lluvia de recriminaciones caía sin cesar sobre estos sacerdotes, cuyos conocimientos escaseaban y, por el contrario, daban muestras de una conducta inadecuada, señalada explícitamente en las relaciones de las visitas pastorales y los registros judiciales (Rapp, 1979:162)2. Los prelados tampoco estaban exentos de la crisis, pues eran más operadores políticos que debían su elevación a los rangos administrativos al favor del príncipe, y en su mayor parte, permanecieron indiferentes a su principal misión: velar por las almas de sus feligreses.

Esta situación de crisis fue denunciada por importantes teólogos, como el inglés John Wyclif (1330-1384). Profesor durante más de treinta años de la Universidad de Cambridge, comenzó a predicar contra los sacerdotes entregados al César, para disimular una querella personal que quedó en punto muerto, luego de que el duque de Lancaster lo apoyase en un proceso instruido por el Obispo de Londres, que tuvo que ser suspendido debido al ruidoso respaldo de sus protectores. Wyclif consideraba que la Iglesia se había arrogado poderes que no eran los suyos, desarrollando una institucionalidad superflua y recomendando estériles prácticas, mientras sus clérigos no practicaban los mandatos de Jesucristo, por lo que recomendaba la intervención del poder civil para erradicar estos males, ya que el monarca tenía por obligación principal hacer respetar, incluso a los proscritos, la ley del Evangelio, por lo que tiene autoridad sobre todos los bautizados que pueblan su reino (Rapp, 1979: 144-145).

Las críticas de Wyclif fueron recogidas más tarde por el teólogo bohemio Jan Hus, quien es considerado como el principal portavoz del movimiento de reforma desarrollado en Bohemia, que encontraría un gran apoyo en círculos de la nobleza, los intelectuales e incluso las clases populares, quienes vieron en la supuesta defensa de la pureza de la fe de los bohemios una importante arma de propaganda. Los husitas señalaban que la nación checa era una síntesis de suelo natal (patria), lengua común (lingua) y ascendencia paterna y materna (sanguis), constituyéndose como la "nación sacrosanta", libre de toda herejía. Dicha condición estimuló la rebelión contra el Sacro Imperio Romano, insultando a los alemanes con apodos como filisteos, idumeos o moabitas (cf. Mitre, 1999: 168-169). Fue tal la popularidad de Hus y de su discípulo Jerónimo de Praga, que su ejecución en la hoguera (1415), los transformó en verdaderos mártires de la causa nacional bohemia, desencadenando una sangrienta guerra que duraría dos décadas y que finalizaría tan solo con un armisticio tras la batalla de Lipany, que generó una precaria paz que se rompería a raíz del barranco generado por las prédicas luteranas.

El autor cita como ejemplo el caso de un cura del obispado de Rodez, quien consultado por el Arzobispo por los artículos del Decálogo, creyó salir de apuros recitando los sacramentos. 


\section{El colapso: Martin Lutero}

En ninguna parte de Europa la conciencia de la necesidad de reformar la Iglesia era más fuerte que en el Sacro Imperio Romano, que enfrentaba una grave crisis a raíz de las segregaciones territoriales que estaba sufriendo. En 1460 Holstein aceptaba la soberanía del rey danés, y seis años más tarde Polonia se había anexado los territorios de la antigua Orden Teutónica. Por otra parte, tras el colapso del ducado de Borgoña en 1477, Francia había reanudado sus tentativas de expansión, a la vez que los cantones suizos se separaban del Imperio y en la Paz de Basilea (1499) consiguieron el reconocimiento de su independencia de facto. Y los ducados austríacos eran amenazados constantemente por la expansión turca (Laffan, 1981: 136). Esa fragmentación política contrastó, sin embargo, con una fuerte actividad cultural. Entre 1490 y 1520 florecieron notablemente las artes del norte, con la aparición de artistas como Alberto Durero, Lucas Cranach y Hans Holbein (Cf. Wittkower, 1981). A la par de este renacimiento artístico, se generó uno intelectual, cuyo máximo portavoz sería el poeta Conrado Celtis, que tradujo la Germania de Tácito y publicó la Tabula Peutingeriana, las obras de la Roswitha de Gandersheim y la epopeya de Barbarroja Ligurinius, iniciando una fuerte corriente de nacionalismo en Alemania (Iserloh en Jedin, 1973: 925-926). Ese nacionalismo se combinó con el espíritu anticlerical del círculo de humanistas de Erfurt, del cual formaban parte intelectuales como Ulrico von Hutten y Croto Rubeanus, quienes se burlaban de la "poca cabeza" de los piadosos y, más aún, de la hipocresía y estrechez de los monjes.

Fue en este ambiente que se produjo el famoso debate por las indulgencias, en el que alcanzaría gran relevancia el monje alemán Martín Lutero, que desde sus sermones de octubre de 1516 tocaba dicho tema. Criticaba duramente esa práctica, considerándola irreconciliable con la salvación evangélica en Cristo. En ese punto, la interpretación del Evangelio de Lutero se reveló fuertemente opuesta a la piedad aceptada por la Iglesia (Atkinson, 1971: 161), pero alcanzó rápidamente una gran popularidad, al punto que Roma decidió reaccionar condenando las tesis luteranas con la bula Exsurge Domine del 15 de junio de 1520, que condenaba 41 de las 95 tesis. Sin embargo, la estrategia papal fracasó, y en ciudades como Maguncia y Colonia los estudiantes aprovecharon las hogueras formadas con los escritos de Lutero para quemar algunos apuntes de sus profesores y tratados escolásticos (Egido, 1992:53-54). La rebeldía de Lutero -quien incluso quemó la bula en la plaza de Wittenberg el 31 de octubre de 1520- y la enorme popularidad que estaba alcanzando, hizo que el papado lo excomulgase por medio de la bula Decet Romanum Pontificem (3 de enero de 1521). No obstante, Carlos V aceptó escucharlo en la Dieta de Worms, donde se le exigió solemnemente que se retractase, pero su negativa hizo que Carlos lo declarase proscrito del Imperio, privándolo de todos sus derechos. Se le dio el tiempo suficiente para que abandonase Worms y regresase 
a Wittenberg, en medio de rumores sobre su supuesto asesinato, convertido en un héroe nacional, algo que solo Alfonso de Valdés, secretario de Carlos, fue capaz de percibir. Este sabía que los alemanes estaban exasperados con las cargas fiscales impuestas por Roma, y por ello culpaban al Papa por no acceder a la petición de un concilio general y preferir su propio interés, y de hecho, la tensión causó serios incidentes en Worms, al punto que algunos príncipes llegaron a los puñetazos (Egido, 2000: 230).

Lutero, sin embargo, estaba vivo, pero temiendo por su vida, el duque sajón Federico "el Sabio" organizó un rapto simulado y condujo al monje rebelde al castillo de Wartburg, donde fue recibido amablemente y fue ocultado bajo el mote de Junker Jorg y presentado a la servidumbre como un amigo del duque. Oculto en el castillo durante más de un año, tradujo la Biblia al dialecto alemán de su Sajonia natal, y un tratado que tituló Sobre los votos monásticos y que publicó en noviembre de 1520. En dicho tratado Lutero criticó las reglas del monacato y definió las órdenes religiosas como un invento humano que no correspondía a lo prescrito por Jesús y lo consideraba una agresión clamorosa contra la fe y la mediación única de este entre Dios y el hombre (Egido, 1992: 63-64). El tratado dio ánimos a muchos monjes, que abandonaron sus votos y contrajeron matrimonio. Ya la Reforma había dejado de ser un debate académico para convertirse en un movimiento nacional, que simbolizaba el creciente nacionalismo alemán.

\section{La Reforma como un movimiento nacional}

Para cuando Lutero publicó la Biblia en alemán, ya su popularidad había traspasado las fronteras de su Sajonia natal. La sátira, los grabados y los pasquines se encargaron de alimentar la oposición a Roma y propagar la heroicidad del "liberador de la tiranía de la curia", encarnada en el Papa. Ya en plena dieta de Worms, Ulrich von Hutten animaba a Lutero con cartas encendidas y divulgaba piezas como Letanía de los alemanes, que eran una parodia de todas las de los santos y de las rogativas, con plegarias contra los enemigos y a favor de la liberación de Alemania, la reforma de la Iglesia y la seguridad del héroe perseguido. El nuncio Alexander, representante del papa en Worms, comunicaba escandalizado la "canonización popular de Lutero" en retratos donde aparecía con diadema santoral, que eran estampas de Hans Baldung Green y adaptadas del retrato de Lucas Cranach "el Viejo", con la leyenda: Martín Lutero, siervo de Jesucristo y nuevo intérprete de la doctrina cristiana (Egido, 2000: 233)3.

También circularon estampas que juntaban a Lutero y Hutten en la misma cara, con una leyenda en latín que rezaba A los luchadores por la libertad cristiana. 
Estos motivos, más o menos teóricos, ganaron la simpatía de los burgueses y los intelectuales de ciudades como Wittenberg, que comenzó a transformarse de golpe. La mendicidad callejera desapareció gracias a la ordenación y racionalización de la asistencia social, financiada con las rentas eclesiásticas desamortizadas. Pero también estalló una furia iconoclasta: se expulsó a los sacerdotes papistas, se quemaron libros litúrgicos e imágenes, y se destruyeron altares, todo con estrépito y con un gran apoyo popular. El popular Karlstadt -nombre adoptado por Andreas Bodenstein, decano de la facultad de Teología donde Lutero realizaba clases- celebró en la navidad de 1521 la primera misa en alemán con la comunión bajo las dos especies, sin ornamentos litúrgicos de ninguna especie, y tras casarse en enero de 1522, pidió enérgicamente que el Consejo de la ciudad retirase las imágenes de las iglesias (Iserloh, 1973: 191).

Los gestos de Carlstadt fueron rápidamente imitados en otras ciudades, alarmando tanto al duque como al propio Lutero, quienes estaban empeñados en proceder pausadamente y ahogar cualquier brote de rebelión. El monje sajón escribió un duro escrito contra los "profetas celestiales", calificándoles de perturbadores de la ordenación social y escandalizadores de los sencillos, pero viendo que esos caudillos seguían activos, viajó a Wittenberg en marzo de 1522 para calmar a la población, pero el descontento persistió y halló eco en la difusión de sus escritos, motivando la rebelión de los caballeros y la guerra del campesinado.

Y no era para menos, pues los profundos cambios en la situación política, económica y social de la Edad Moderna empobrecieron fuertemente a caballeros y campesinos. A medida que la economía natural iba siendo sustituida por la economía del dinero, el feudalismo personal por el Estado territorial y burocrático y el ejército de caballeros por tropas asalariadas, por tropas mercenarias dotadas de armas de fuego y cañones, obligando a los caballeros a emprender disimulados saqueos, entrar al servicio de un señor o levantarse a sí mismo a la posición de príncipe territorial, lo cual solo era posible mediante una rebelión contra los curas, iniciativa que logró el apoyo de Franz von Sickingen, un gran amigo de Hutten, quien obligó a los domínicos del Alto Rin a ceder en la polémica con aquel gran humanista. Sus castillos se convirtieron en lugares de refugio para varios reformadores, como Ecolampadio y Butzer, pero nunca logró entender realmente los postulados de Lutero, a pesar de que se declaró partidario de sus doctrinas. En cambio, era impulsado por la idea de lucha por la libertad y justicia alemana, tal como ellos la entendían, es decir, eliminar a los señores feudales eclesiásticos (Iserloh, 1973: 182-183), y decidió atacar al arzobispo de Tréveris, Richard von Glienffekau. Su tentativa resultó un fracaso, y tras la derrota de Sickingen en Landstuhl (7 de mayo de 1523), las tropas imperiales devastaron en solo un mes y medio 32 castillos y pa- 
lacios en Odewald y la Franconia de Würtemberg, quedando aniquilada la caballería como fuerza del Imperio.

La revuelta campesina -o Guerra del Campesinado (1524-1525), como la denomina la historiografía alemana- tiene un prisma distinto. Se trató de una protesta, casi siempre violenta y armada, de descontentos que, en sociedades agrarias y sacralizadas como lo eran las del Sacro Imperio, era mayoritariamente campesina y envuelta en motivaciones religiosas. Pero había causales más profundas del descontento campesino, que había desembocado en violentas protestas durante más de tres décadas, todas reprimidas mediante la fuerza bruta y con fracasos desastrosos, sin aportar ningún efecto positivo, pero trayendo consigo sufrimientos e injusticias aún peores. El campesinado imperial estaba oprimido por impuestos legales, e incluso algunos ilegales, y el aumento de las riquezas y el lujo generado por el descubrimiento de América empeoró aún más su situación, llevando a los campesinos a organizarse en asociaciones clandestinas como los Kaasbroder ("hermanos del queso" holandés) o la Bundschuh (por los zapatos con cordones de los campesinos, que los diferenciaba de los zapatos con hebilla de sus amos) (Cf. Atkinson, 1971: 269-270). Las doctrinas teológicas de la Reforma removieron grandes añoranzas en los corazones y mentes de los alemanes, así como un descontento más profundo con la situación imperante. Sin embargo, los campesinos cometieron un error que a la larga sería trágico: identificar la causa religiosa de Lutero con su propia causa social y económica. Careciendo de una jefatura militar competente (estaban guiados por el revolucionario Thomas Müntzer), sin una estrategia planificada o coherente, los campesinos vagaban saqueando y robando, hasta que fueron literalmente exterminados en la batalla de Frankenhausen (12 de junio de 1525). Los sobrevivientes fueron ahorcados o mutilados, las viudas y los huérfanos quedaron desamparados, los conventos fueron quemados; los pueblos, arrasados; el ganado, exterminado y los útiles de trabajo fueron destruidos (Atkinson, 1971: 277).

Del fracaso de estos movimientos revolucionarios, surgió una consecuencia importante. La Reforma ya no era un movimiento religioso o un debate teológico. Estaba quedando subordinada a los procesos políticos, sociales y culturales contemporáneos, empequeñeciendo la autoridad de Lutero a raíz de la complejidad y violencia de los movimientos seculares, que el reformador no podía controlar. Ese factor fundamental fue el que facilitó la expansión de la Reforma por el continente europeo.

\section{La expansión de la Reforma}

El fracaso de las revueltas de los caballeros y de los campesinos llevó al movimiento de la Reforma a una fuerte dependencia del poder secular. Lutero y sus colaboradores aprobaban sin reservas las intervenciones ordenancistas 
de los príncipes, que podían ser considerados como "obispos de urgencia". Desde esa perspectiva, se impuso, paso a paso, un sistema de iglesias territoriales dirigidas desde el poder secular, a través de las visitaciones, que reordenaron la organización territorial en un nuevo sentido, favoreciendo la rápida expansión de la Reforma en los territorios imperiales (Lutz, 2008: 73).

El ensanchamiento del sistema político-administrativo y de su campo de acción, unido a la creciente sacralización de la figura del gobernante, reforzaron la soberanía y la estabilizaron en un punto decisivo en la etapa de formación de las nuevas monarquías. El emergente Estado soberano debió luchar contra los tradicionales opositores al Estado centralizado: la nobleza, el clero y las ciudades semiautónomas. La Reforma facilitó el monopolio de la Iglesia y la religión, facilitando el control del aparato militar e impositivo. Lo mismo ocurrió con el culto a la personalidad del líder, sacralizándolo con el apoyo del clero, que se convirtió en el brazo de control ideológico del Estado.

Por esa razón, las ciudades del Sacro Imperio adoptaron paulatinamente la Reforma, y a mediados de 1525 ya se habían convertido importantes metrópolis comerciales como Bremen, Constanza, Nüremberg y Magdeburgo, tendencia que fue seguida por las ciudades hanséaticas del norte. Era un cambio comprensible, pues las críticas a la Iglesia Católica eran más fuertes en las ciudades imperiales, donde las corrientes humanistas y reformadoras penetraron con mayor facilidad y la lectura era más habitual. Y, por otra parte, los dirigentes vieron reforzado su poder, a la vez que los ciudadanos se veían libres de presiones fiscales o podían ver cómo el dinero fiscal se invertía en obras sociales o educativas.

Los príncipes fueron también conscientes de las ventajas materiales que ofrecía el dominar las rentas eclesiásticas para diferentes iniciativas. Dado que estos señoríos multiformes constituían auténticos Estados, y que el señor, de forma provisional primero -y luego definitiva-, se convertía en jefe responsable (obispo laico) de su propia iglesia. Al final de la vida de Lutero, su reforma se había adueñado del norte de Alemania y de la zona báltica, permaneciendo solo leales a Roma el principado de Baviera -regido por el clan Wittelsbach-y los principados directamente vinculados a los Habsburgo.

\section{La polarización}

Otro elemento clave que facilitó la rápida difusión de la Reforma fue la ausencia del Emperador Carlos V, quien estaba ocupado en la guerra contra los franceses por el control de la península itálica. El regente -su hermano Fernando- también se vio maniatado y debió postergar el problema religioso debido a la constante amenaza de un imperio otomano en plena expansión, que llegó a controlar Hungría tras su decisiva victoria en Mohács (1526). 
La fortaleza de los protestantes se reveló en su máxima expresión en la primera Dieta de Spira (1526), donde Fernando se vio obligado a realizar numerosas concesiones a pesar de las enérgicas advertencias de su hermano Carlos, cediendo el derecho de opción a los poderes políticos y su conciencia. Los protestantes -liderados por los duques de Hesse y Sajonia- no ocultaban su entusiasmo por su causa, perfilándose una poderosa alianza militar frente a los posibles contraataques de Carlos V. Incluso más, cuando en una segunda dieta en Spira (1529), el emperador quiso terminar esa política tolerante, los príncipes y las ciudades reformadas elevaron una enérgica protesta contra la voluntad imperial (Egido, 1992: 92) .

No obstante, protestantes y católicos buscaban solucionar pacíficamente el conflicto para aglutinar fuerzas contra la amenaza turca, y en la importante dieta de Augsburgo (1530) los protestantes presentaron la Confessio Augustana o "confesión de Augsburgo", elaborada por uno de los principales discípulos de Lutero -Felipe Melanchton-y acordada por los teólogos de Wittenberg. Sin embargo, la dieta resultó un rotundo fracaso debido a que los católicos se negaron a ceder en concordia. A Carlos $V$ no le quedó más alternativa que colocarse del lado católico y no pudo ni enterarse de la "Defensa" posterior de Melanchton contra la amalgama del teólogo Johann Eck, que concluía por declarar el documento como una herejía. Se imponía así la voluntad pontificia sobre cualquier intento de conciliación.

En este ambiente polarizado, los protestantes ya se estaban organizando desde 1529 para hacer frente a las iniciativas imperiales, formando la Liga de Esmacalda en 1531, bajo el liderazgo de Felipe de Hessen y conformada por importantes ciudades como Estrasburgo, Bremen, Ulm y Lübeck. En 1532 se unió Francia y seis años más tarde lo hizo Dinamarca. La liga ${ }^{5}$ logró una organización racional, capaz de dotar de mandos, de soldados y de recursos, en caso de necesidad, a un ejército considerable. La liga logró importantes objetivos, como la conversión del ducado de Brusnwick y la secularización de los obispados-principados de Münster, Minden, Osnabrück y Padernborn. El Palatinado y Colonia se convirtieron también al luteranismo y se adhirieron a la Liga, ante lo cual Carlos $V$ reaccionó alarmado, pues se desequilibró la fuerza del electorado imperial en favor de los protestantes, amenazando seriamente las ambiciones de Carlos de declarar el trono imperial como patrimonio hereditario de los Habsburgo. Pero el curso de los acontecimientos dio un giro radical en 1544, pues Carlos V había firmado la paz de Crépy con los franceses, mientras que Felipe de Hessen debió hacer concesión tras concesión por su pública

4 Desde este manifiesto, comenzó a usarse el apelativo de protestantes, para llamar a los luteranos.

5 Una liga era una alianza entre múltiples Estados, más grande que la alianza tradicional. 
bigamia, delito castigado con la pena capital. La diplomacia imperial logró un gran éxito al conseguir la alianza de Mauricio de Sajonia, cuyo luteranismo era solo nominal, a cambio de tierras en la otra Sajonia, gobernada por su tío Juan Federico, y la transferencia de la dignidad electoral de éste.

Con la adhesión de Mauricio, Carlos V aisló a la liga y pudo pasar a la acción, publicando en 1548 un edicto condenatorio contra Juan Federico y Felipe, por ocupar y usurpar el ducado de Brunswick. La guerra concluyó con la gran victoria de las tropas imperiales en la batalla de Mühlberg (24 de abril de 1547), donde los protestantes fueron masacrados por la caballería imperial. Sin embargo, Carlos $V$ no logró reducir a los principados protestantes a la obediencia católica, más aún cuando el papa Pablo III rompió con Carlos V por los celos provocados por su victoria, y suspendió en febrero de 1548 el recién convocado Concilio en Trento, desentendiéndose del problema alemán. El Emperador se vio forzado a aceptar una nueva tregua en el llamado Interim de Augsbugo, aceptando las reformas emprendidas por los príncipes en sus territorios. Asimismo, las ciudades del norte lograron resistir y en Magdeburgo se inició una propaganda xenófoba que atacaba a los españoles y a Mauricio de Sajonia (Egido, 1992: 44). Y Mauricio de Sajonia, receloso ante la inseguridad de las ventajas prometidas por Carlos $V$, inició negociaciones con los protestantes y el rey Enrique II de Francia, logrando la alianza de ambos sectores a cambio de la entrega a Francia de las plazas de Metz, Toul y Verdún. El archiduque Fernando, por su parte, no cesaba de intrigar, temiendo que el título imperial pasase a Felipe II. Todo ello condujo a un nuevo estallido bélico en 1552, que obligó a Carlos a escapar de Innsbruck a Viena y renegociar, más aún cuando sus tropas fracasaron al asediar Metz, siendo derrotados por los franceses.

En ese clima de cansancio se debe inscribir el decisivo acuerdo entre católicos y protestantes: la paz de Augsburgo de 1555, que significó el fracaso de los ideales unificadores de Carlos. Ni los príncipes ni el emperador podían perturbar a los Estados o a los señores, pero la libertad de confesión solo se permitía a los príncipes, aunque los súbditos podían exiliarse sin perder sus bienes $u$ honra a otro Estado donde se profesase la misma confesión religiosa. En las ciudades, católicos y protestantes debían ser respetados y nadie sería inquietado en el libre ejercicio de sus ritos y costumbres, en la propiedad y uso de sus bienes.

\section{Conclusión}

Aunque durante el siglo XVI se recuperaron los antiguos patrones de valores grecolatinos, la unión entre sociedad y religión no se perdió. En este contexto deben entenderse las críticas emitidas por intelectuales y teólogos a la crisis cultural y moral que sufría la Iglesia desde el siglo XIV, y que conducirían a la definitiva irrupción de la Reforma Protestante en el Sacro Imperio Romano a partir de las prédicas del monje sajón Martín Lutero. 
Las ideas revolucionarias de Lutero conquistaron desde un principio las simpatías no solo de intelectuales y teólogos, sino también de los gobernantes, quienes ambicionaban el control de las jugosas rentas generadas por la Iglesia en sus principados, que habían aumentado considerablemente gracias a la venta de las indulgencias. Ello favoreció la rápida expansión del luteranismo, y su pervivencia aun después de la masacre de Mühlberg, llegando al reconocimiento final de la confesión protestante en la paz de Augsburgo.

El éxito del protestantismo en el Sacro Imperio Romano motivó a los monarcas de los nacientes Estados Modernos a adoptar las ideas reformadas, que fueron difundidas desde Wittenberg por los diferentes teólogos que habían acudido a estudiar a su universidad, penetrando en Escandinavia, Suiza, Francia e incluso en las Islas Británicas, iniciando un antagonismo con España, que llevaría al distanciamiento entre ambas potencias, tradicionalmente aliadas, y a una guerra abierta a fines del siglo XVI, con consecuencias visibles en la colonia de Chile, que debió hacer frente a las correrías de corsarios como Francis Drake, Thomas Cavendish y John Hawkins.

\section{Referencias bibliográficas}

Atkinson, J. (1971). Lutero y el nacimiento del protestantismo. Madrid: Alianza Editorial.

Egido T. (1992). Las reformas protestantes. Madrid: Síntesis.

Egido T. (2000). "Carlos V y Lutero", en Castellano, Castellano, J.L. y Sánchez Montes, J.L. (coords.). Carlos V. Europeísmo y universalidad (Vol. V, Religión, cultura y mentalidad). Granada: Sociedad Estatal para la Conmemoración de los Centenarios de Carlos V y Felipe II y Universidad de Granada, pp. 225-249.

Iserloh, E. (1973). "El humanismo alemán", en Jedin, H. (dir.). Manual de Historia de la Iglesia (vol. IV). Barcelona: Herder, pp. 922-937.

Lutz, H. (2008). Reforma y Contrarreforma. Madrid: Alianza Editorial.

Mitre Fernández, E. (2007). Iglesia, herejía y vida política en la Europa medieval. Madrid: Biblioteca de Autores Cristianos.

Rapp, F. (1979). La Iglesia y la vida religiosa en Occidente a finales de la Edad Media. Barcelona: Labor.

Wittkower, R. y otros (1981). "Las artes en la Europa Occidental", en Potter, George Richard (ed.). Historia del Mundo Moderno (vol. I, El Renacimiento 14931520). Barcelona: Sopena, pp. 127-153. 